\title{
Use of Ethylenediaminetetraacetic Acid as a Scavenger for Chromium from "Wet Blue" Leather Waste: Thermodynamic and Kinetics Parameters
}

\author{
José E. Resende, ${ }^{1}$ Mateus A. Gonçalves, ${ }^{1}$ Luiz C. A. Oliveira, ${ }^{2}$ \\ Elaine F. F. da Cunha, ${ }^{1}$ and Teodorico C. Ramalho ${ }^{1,3}$ \\ ${ }^{1}$ Departamento de Química, Universidade Federal de Lavras, Caixa Postal 3037, 37200-000 Lavras, MG, Brazil \\ ${ }^{2}$ Departamento de Química, ICEx, UFMG, Campus-Pampulha, 31270-901 Belo Horizonte, MG, Brazil \\ ${ }^{3}$ Biomedical Research Center, University Hradec Kralove, Hradec Kralove, Czech Republic \\ Correspondence should be addressed to Teodorico C. Ramalho; teo@dqi.ufla.br
}

Received 3 July 2014; Revised 2 September 2014; Accepted 4 September 2014; Published 11 December 2014

Academic Editor: Davut Avci

Copyright @ 2014 José E. Resende et al. This is an open access article distributed under the Creative Commons Attribution License, which permits unrestricted use, distribution, and reproduction in any medium, provided the original work is properly cited.

\begin{abstract}
One serious consequence of the current consumer society is the transformation of the environment into a waste receptacle arising from human activities. Because of the potential toxic effects of chromium solid waste containing this metal there are grounds for serious concern for the tanning and leather processing industry. The application of tannery waste as organic fertilizer has led to extensive contamination by chromium in agricultural areas and may cause the accumulation of this metal in soils and plants. This work evaluated the extraction of $\mathrm{Cr}^{+3}$ and $\mathrm{Cr}^{+6}$ contained in solid waste from the leather industry through density functional theory (DFT) calculations. The Gibbs free energy calculations reveal that the chelator ethylenediaminetetraacetic acid (EDTA) forms more stable complexes with metal ions of chromium compared with the structures of the complexes $\left[\mathrm{Cr}(\mathrm{NTA})\left(\mathrm{H}_{2} \mathrm{O}\right)_{2}\right]$ and $[\mathrm{Cr}$-collagen], the latter used to simulate the protein bound chrome leather.
\end{abstract}

\section{Introduction}

Chromium compounds are used in various industrial processes such as the manufacture of dyes, paints, leather tanning, and plating [1]. Although most of the waste from these processes contains $\mathrm{Cr}^{+3}$, which is much less toxic than $\mathrm{Cr}^{+6}$, there is the concern expressed about the possible mutagenic and carcinogenic risks of $\mathrm{Cr}^{+6}$ formed as a result of $\mathrm{Cr}^{+3}$ chemical oxidation [2]. Presence of light, heat, $\mathrm{pH}$ above 5, and reaction with the oxidized fat are some of the situations that cause the oxidation of $\mathrm{Cr}^{+3}$ to $\mathrm{Cr}^{+6}$ [3], since, in basic solutions, the oxidation by oxidants such as peroxide occurs more easily [4]. However, the use of chromium in some industry sectors, including mainly the leather industry, due to lack of new processes that can compete with those based on Cr chemistry, is unlikely to be abandoned, in terms of both costs and the quality of the final product [1].

In tanneries, the animal skin goes through processing steps preparing it for the tanning process. The "wet blue" leather, as the chrome tanned leather is called, has a chromium content of $20 \mathrm{~g} \cdot \mathrm{L}^{-1}$ and its function is to act as a bridge, linking the protein groups of leather, providing greater end product mechanical and chemical stability [5]. Surveys conducted have shown that approximately 600,000 tons of solid waste is produced each year worldwide by the leather industry and about $40-50 \%$ of all leather obtained is lost in shavings [6]. These shavings are small pieces of leather in a variety of forms, mainly composed of collagen complexed with chromium [7]. However, all the methods available for reuse of the tanned leather residue require drastic treatments, chemical or thermochemical processes, causing the complete hydrolysis of leather and adding little value to the final material [8].

In recent years, a viable alternative to recycle these wastes is gaining prominence as an excellent solution to the problem [8]. It is the transformation of the waste (splinters, flaps, and sanding dust) into nitrogen-rich fertilizer. The method consists of the complete dissolution of the solid, removing 
<smiles>O=C(O)CN(CCN(CC(=O)O)CC(=O)O)CC(=O)O</smiles>

(a)

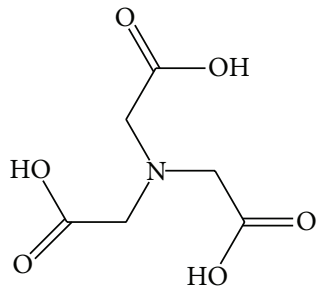

(b)

FIgURE 1: Structure of the EDTA (a) and NTA (b).

the precipitate as Cr hydroxide, and use of the protein remaining in the organic liquid as fertilizer [8]. A crucial step in the realization of the method is the use of sequestering agents which may complex the chromium from the organic matter of the leather, consisting mainly of collagen.

Among the most important classic reagents containing many industrial applications which can be used to remove toxic metal ions from contaminated water and soil stand out ethylenediaminetetraacetic acid (EDTA) [9-12] and nitrilotriacetic acid (NTA) [13-15] (Figure 1). These ligands, in the form of alkali metal salt, contain the respective polyacetate anion forming very stable complexes with most metallic ions. The evidenced importance of these ligands as chelating agents supports the need for an exploration of their properties. Given these concepts, theoretical studies concomitant with the experimental, addressing the understanding of the phenomenon involving a metal complexation by organic ligands, are always needed. However, due to the variety of possible geometries and different oxidation states of the metal, theoretical calculations for metal complexes are generally complicated [16]. The ab initio calculations (Hatree-Fock) [17] used to describe the complexes formed between metals and organic ligands are limited by the complexity of the system being studied. On the other hand, the method of the density functional theory (DFT) has been increasingly used to study interactions between biomolecules and metals $[18,19]$. This approach is interesting because it includes the effect of electron correlation and enables the calculation for larger systems $[20,21]$. Thus, the objective of this work is to use molecular modeling methods and DFT calculations to evaluate the thermodynamics of formation of $\mathrm{Cr}^{+3}$ and $\mathrm{Cr}^{+6}$ complexes formed by EDTA and NTA ligands, relating them to the respective structures of $\mathrm{Cr}$-collagen complex used to simulate the interaction between the protein leather and chrome. In addition, experimental kinetics studies were carried out in order to obtain the kinetics parameters for the studied complexes.

\section{Computational Methods}

Initially, the structures of ligands and complexes were modeled using the PC Spartan Pro program [22]. The models were submitted to optimization by the semiempirical and DFT methods, PM3 [23], and BP86/6-31G for the atoms C,

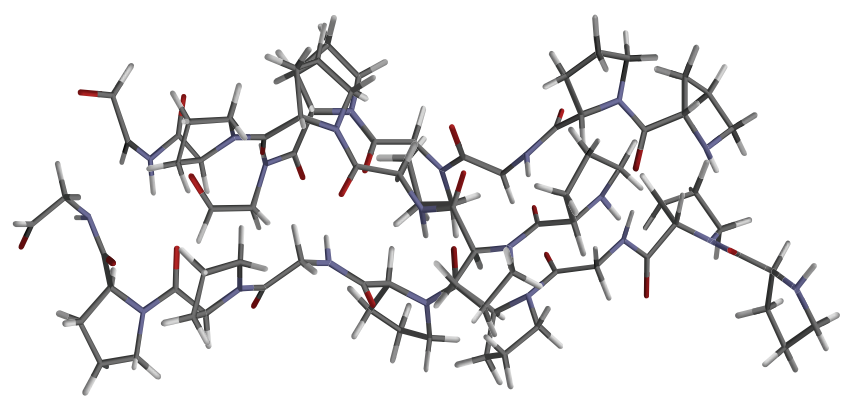

FIGURE 2: Structure of collagen. The red color represents the oxygen atom; blue: nitrogen, gray: carbon, and white: hydrogen.

$\mathrm{H}, \mathrm{O}$, and $\mathrm{N}$ and LANL2DZ for the metal. To simulate the interaction between the target protein and chromium ions, the three-dimensional structure of collagen was obtained from Protein Data Bank (PDB) (http://www.rcsb.org/pdb) (code: 1A3I), Figure 2.

This protein has been used as a model structure for studies of collagen [24], the most abundant protein in mammals and responsible for the complexation of chromium in the leather [25]. Because of the size of this protein, there was a possibility of complexation with two or even three chromium atoms. However, this work focuses on the complexation reaction for a Cr-ligand ratio of $1: 1$. Thus, the protein structure was adjusted by cutting the edges, altering the size of the structure to an approximate radius of $17 \AA$. To investigate the thermodynamic properties of the complexation between chromium $\left(\mathrm{Cr}^{+3}\right.$ and $\left.\mathrm{Cr}^{+6}\right)$ and the ligands EDTA, NTA, and collagen, electronic structure calculations were performed on another level. For this, all structures were exported to the GAUSSIAN 09 [26] program, where the vibrational frequency calculations were performed using the method of Density Functional Theory (DFT) $[12,27]$ combined with functional exchange-correlation (XC) BP86 [28]-expression Becke for exchange and Perdew for correlation - and the basis set 6-31G [29] for the atoms $\mathrm{C}, \mathrm{H}, \mathrm{O}$, and $\mathrm{N}$ and LANL2DZ $[30,31]$ for the chromium atom. The latter, by including pseudopotential, is indicated for atoms that are from the fourth period of the periodic table.

The complexation of a metal ion with a chelating agent usually occurs in aqueous medium. In order to simulate 


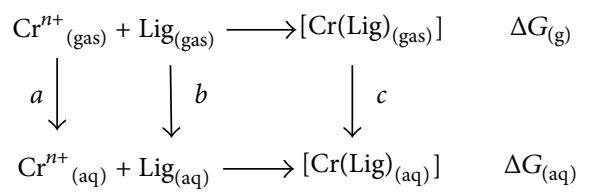

FIGURE 3: Thermodynamic cycle.

this situation, we have employed a thermodynamics cycle (Figure 3). Since the theoretical calculations were performed for the gaseous state and the interest is in obtaining the free energy of reaction in solution, a new series of calculations were performed in GAUSSIAN 09 to evaluate the solvation energy of the species involved. The solvent effects have been taken into account with the Polarazible continuum model (PCM) developed by Shimizu et al. [32]. To get the Gibbs free energy of complexation reaction solution $\left(\Delta G_{(\mathrm{aq})}\right)$ shown in Table 1, calculations were made using the thermodynamic cycle below $[12,18]$ and the following:

$$
\Delta G_{(\mathrm{aq})}=\Delta G_{(g)}+[c-(a+b)],
$$

where $a=\Delta G_{\text {solv }}\left(\mathrm{Cr}^{n+}\right), b=\Delta G_{\text {solv }}(\mathrm{Lig})$, and $c=\Delta G_{\text {solv }}$ ([Cr(Lig)]).

To justify the difference in stability between the complexes, analysis of natural bond orbitals (NBO) [33] was performed with the BP86 functional and the basis functions 6-31G (C, H, O, N) and SDD [34] (Cr). Furthermore QTAIM calculations were carried out by using the program AIM11 [35].

2.1. Experimental. To evaluate the kinetics of complexation of trivalent chromium with EDTA [36] the following reagents were used: Merck PA: chromium salt $\left(\mathrm{Cr}\left(\mathrm{NO}_{3}\right)_{3} \cdot 9 \mathrm{H}_{2} \mathrm{O}\right)$ and EDTA (disodium). Furthermore, we used thermostatic bath (Tecnal TE-210) and an UV-Vis spectrophotometer (Shimadzu UV-160 1PC). For the Cr-EDTA complex formation (2), $\mathrm{Cr}^{3+}$ and EDTA solutions were prepared at concentrations of 1000 and $7158 \mathrm{ppm}$, respectively, so that the stoichiometry of the reaction $1: 1$ was obeyed:

$$
\mathrm{Cr}_{(\mathrm{aq})}^{3+}+\operatorname{EDTA}_{(\mathrm{aq})}^{4-} \longrightarrow \underset{(\text { violet color })}{\left[\mathrm { Cr } \left(\mathrm{EDTA}_{(\mathrm{aq})} .\right.\right.}
$$

$5 \mathrm{~mL}$ of each solution was placed in contact in several containers with in order to measure the absorbance of the solution at different reaction times. The temperature was controlled by a thermostatic bath using temperatures of 25 , $40,50,60$, and $70^{\circ} \mathrm{C}$. After removing the sample from thermostatic bath it was placed in an ice bath to stop the reaction and the solution was read in a UV-Vis spectrophotometer.

\section{Results and Discussion}

3.1. EDTA and NTA Complex with the Cr Ion. The EDTA ligand is hexadentate and the atoms responsible for coordinating with the chrome are four oxygen atoms of the carboxylic groups and two nitrogen atoms of the amine groups. In order to develop different isomers of Cr-EDTA complex, relative
TABLE 1: Variation of the Gibbs free energy for complexation reaction in $\mathrm{kcal} \cdot \mathrm{mol}^{-1}$

\begin{tabular}{lccc}
\hline Complex & Charge on the Cr atom & $\Delta G_{(\mathrm{aq})}$ & $\Delta \Delta G_{(\mathrm{aq})}$ \\
\hline$[\mathrm{Cr}(\mathrm{EDTA})]$ & +6 & -322.75 & 0.00 \\
{$[\mathrm{Cr}(\mathrm{EDTA})]$} & +3 & -316.99 & 5.76 \\
{$\left[\mathrm{Cr}(\mathrm{NTA})\left(\mathrm{H}_{2} \mathrm{O}\right)_{2}\right]$} & +6 & -311.02 & 11.73 \\
{$\left[\mathrm{Cr}(\mathrm{NTA})\left(\mathrm{H}_{2} \mathrm{O}\right)_{2}\right]$} & +3 & -305.93 & 16.82 \\
{$[\mathrm{Cr}($ collagen $)]$} & +6 & -289.70 & 33.05 \\
{$[\mathrm{Cr}($ collagen $)]$} & +3 & -286.66 & 36.09 \\
\hline
\end{tabular}

positions between the two nitrogen atoms in the structures were considered. However, for structures that are initially different in the disposition of the atoms in the coordination sphere, after optimization and minimization of energy, it was found that all converged into a common structure with a more stable rearrangement (Figure 4(a)). Regarding the NTA, coordination occurs between three carboxyl groups and the nitrogen and thus a tetradentate ligand. In this case, as the objective was to investigate complexes with octahedral geometry, since they tend to be more stable, for development of the structures two water molecules were used as ligand, thus completing the valence six of the chromium. As with EDTA, after optimization of the structure, all converged into a single (Figure 4(b)).

3.2. Free Energy Calculations. After optimization, all calculations of frequency (in the gaseous state and implicit solvent) were performed in GAUSSIAN 09 program, as mentioned in the methodology section. Thus, it was possible to obtain the Gibbs free energy total for each species as per

$$
G_{\mathrm{tot}}=\sum_{E, T, G}+E_{\mathrm{corr}(G)}+E_{\mathrm{ZPE}}
$$

where $G_{\text {tot }}=$ Gibbs free energy of the total, $\sum_{E, T, G}=$ sum of electronic, thermal, and free Gibbs energy, $E_{\operatorname{corr}(G)}=$ Gibbs free energy correction, and $E_{\mathrm{ZPE}}=$ zero-point energy correction.

From the total free energy values $\left(E_{\text {tot }}\right)$ of the species (reactants and products), it was possible to perform the calculation of the thermodynamic cycle and find the change in free energy for each complexation reaction in solution $\left(\Delta G_{(\mathrm{aq})}\right)$ and the corresponding relative free energy change $\left(\Delta \Delta G_{(\mathrm{aq})}\right)$, as shown in Table 2.

According to the results shown in Table 3, the stability order for the complexes is as follows: $\left[\mathrm{Cr}^{+6}(\right.$ EDTA)] > $\left[\mathrm{Cr}^{+3}(\mathrm{EDTA})\right]>\left[\mathrm{Cr}^{+6}(\mathrm{NTA})\left(\mathrm{H}_{2} \mathrm{O}\right)_{2}\right]>\left[\mathrm{Cr}^{+3}(\mathrm{NTA})\left(\mathrm{H}_{2} \mathrm{O}\right)_{2}\right]$ $>\left[\mathrm{Cr}^{+6}(\right.$ collagen $\left.)\right]>\left[\mathrm{Cr}^{+3}\right.$ (collagen $\left.)\right]$. This means that the complexation reaction between chromium and EDTA is more favorable to occur in relation to the complexes $\left[\mathrm{Cr}(\mathrm{NTA})\left(\mathrm{H}_{2} \mathrm{O}\right)_{2}\right]$ and Cr-collagen, for both oxidation states of the chromium. It may also be noticed that, for the same ligand, the complex formed with $\mathrm{Cr}^{+6}$ is more stable when compared to the corresponding complex with $\mathrm{Cr}^{+3}$. This is due to the fact that there is a correlation between the complexation capacity and size of the metal ion, because the metal-ligand affinity proves to be the inverse of the ionic radius [37]. Thus, 


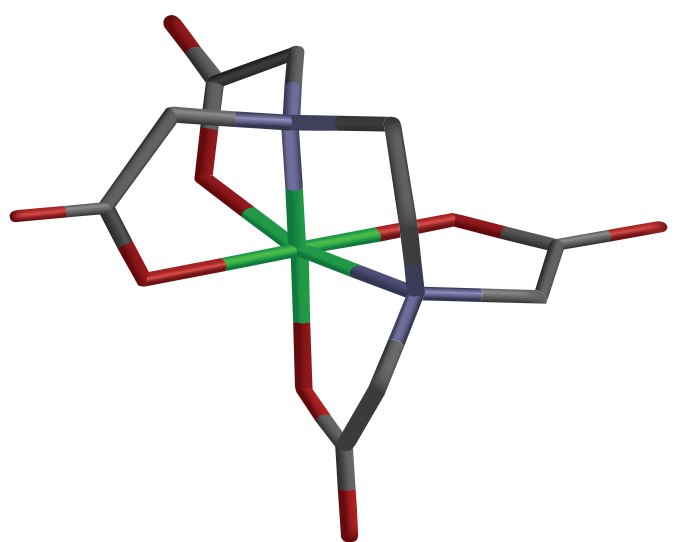

(a)

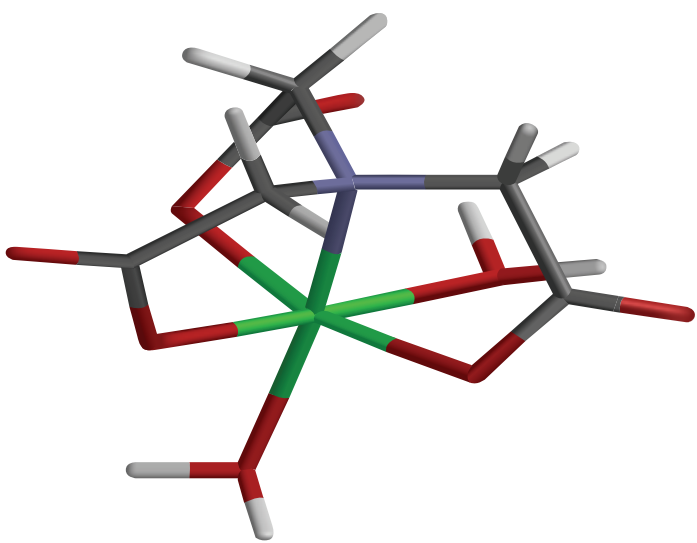

(b)

Figure 4: Optimized structures of the complexes [Cr(EDTA)] (a) and $\left[\mathrm{Cr}(\mathrm{NTA})\left(\mathrm{H}_{2} \mathrm{O}\right)_{2}\right]$ (b). The green color represents the chrome atom; red: oxygen, blue: nitrogen, and gray: carbon.

TABLE 2: Relative Gibbs free energy values for the complexation reaction in solution $\left(\Delta \Delta G_{(\mathrm{aq})}\right)$.

\begin{tabular}{lcc}
\hline Complex & Chromium load & $\begin{array}{c}\Delta \Delta G_{(\mathrm{aq})} \\
\mathrm{kcal} \cdot \mathrm{mol}^{-1}\end{array}$ \\
\hline$[\mathrm{Cr}(\mathrm{EDTA})]$ & +6 & 0.00 \\
{$\left[\mathrm{Cr}(\mathrm{NTA})\left(\mathrm{H}_{2} \mathrm{O}\right)_{2}\right]$} & +6 & 11.73 \\
{$[\mathrm{Cr}($ collagen $)]$} & +6 & 33.50 \\
\hline$[\mathrm{Cr}(\mathrm{EDTA})]$ & +3 & 5.76 \\
{$\left[\mathrm{Cr}(\mathrm{NTA})\left(\mathrm{H}_{2} \mathrm{O}\right)_{2}\right]$} & +3 & 16.82 \\
{$[\mathrm{Cr}($ collagen $)]$} & +3 & 36.09 \\
\hline
\end{tabular}

TABLE 3: QTAIM parameters obtained by the main interatomic interactions in the isomer (B) of the Cr-EDTA complex, the Cr$\operatorname{NTA}\left(\mathrm{H}_{2} \mathrm{O}\right)_{2}$, and Cr-collagen complex in a.u.

\begin{tabular}{|c|c|c|c|c|}
\hline & BCP & $\rho$ & $\nabla^{2} \rho$ & $\mathrm{Hc}$ \\
\hline \multirow{5}{*}{ Cr-EDTA } & $\mathrm{Cr}-\mathrm{O} 1$ & 0.175 & +0.649 & -0.064 \\
\hline & $\mathrm{Cr}-\mathrm{O} 2$ & 0.122 & +0.533 & -0.018 \\
\hline & $\mathrm{Cr}-\mathrm{O} 3$ & 0.135 & +0.777 & -0.025 \\
\hline & $\mathrm{Cr}-\mathrm{O} 4$ & 0.170 & +0.488 & -0.062 \\
\hline & O1-C5 & 0.273 & -0.449 & -0.270 \\
\hline \multirow{5}{*}{$\mathrm{Cr}-(\mathrm{NTA})\left(\mathrm{H}_{2} \mathrm{O}\right)_{2}$} & $\mathrm{Cr}-\mathrm{O} 2$ & 0.035 & +0.100 & -0.007 \\
\hline & $\mathrm{Cr}-\mathrm{O} 5$ & 0.052 & +0.135 & -0.017 \\
\hline & $\mathrm{Cr}-\mathrm{O} 8$ & 0.081 & +0.198 & -0.033 \\
\hline & $\mathrm{Cr}-\mathrm{O} 9$ & 0.086 & +0.241 & -0.034 \\
\hline & Cr-N11 & 0.099 & +0.236 & -0.039 \\
\hline \multirow{4}{*}{ Cr-collagen } & $\mathrm{Cr}-\mathrm{O} 1$ & 0.055 & +0.087 & -0.008 \\
\hline & $\mathrm{Cr}-\mathrm{O} 2$ & 0.055 & +0.068 & 0.009 \\
\hline & $\mathrm{Cr}-\mathrm{O} 3$ & 0.058 & +0.067 & -0.012 \\
\hline & $\mathrm{Cr}-\mathrm{O} 4$ & 0.086 & +0.046 & -0.031 \\
\hline
\end{tabular}

the results are consistent with the difference in size between the ions, 0.76 [38] and $0.44 \AA$ [39] for $\mathrm{Cr}^{+3}$ and $\mathrm{Cr}^{+6}$, respectively. In addition, molecular orbital and electronic structure
TABLE 4: Higher energies of nonbonding interactions between NBOs in the coordination sphere for complexes of $\mathrm{Cr}^{+6} \mathrm{kcal} \cdot \mathrm{mol}^{-1}$.

\begin{tabular}{ccllll}
\hline \multicolumn{2}{c}{$\mathrm{Cr}^{+6}(\mathrm{EDTA})$} & \multicolumn{2}{c}{$\mathrm{Cr}^{+6}(\mathrm{NTA})\left(\mathrm{H}_{2} \mathrm{O}\right)_{2}$} & \multicolumn{2}{c}{$\mathrm{Cr}^{+6}$ (collagen) } \\
\hline$n_{\mathrm{O} 4} \rightarrow \mathrm{d}^{*}{ }_{\mathrm{Cr}}$ & 9.11 & $n_{\mathrm{O} 8} \rightarrow \mathrm{d}^{*}{ }_{\mathrm{Cr}}$ & 4.45 & $n_{\mathrm{O} 3} \rightarrow \mathrm{d}^{*}{ }_{\mathrm{Cr}}$ & 2.81 \\
$n_{\mathrm{O} 1} \rightarrow \mathrm{d}^{*}{ }_{\mathrm{Cr}}$ & 7.15 & $n_{\mathrm{O} 5} \rightarrow \mathrm{d}^{*}{ }_{\mathrm{Cr}}$ & 3.90 & $n_{\mathrm{O} 1} \rightarrow \mathrm{d}^{*}{ }_{\mathrm{Cr}}$ & 2.63 \\
$n_{\mathrm{O} 2} \rightarrow \mathrm{d}^{*}{ }_{\mathrm{Cr}}$ & 6.44 & $n_{\mathrm{O} 2} \rightarrow \mathrm{d}^{*}{ }_{\mathrm{Cr}}$ & 3.74 & $n_{\mathrm{O} 2} \rightarrow \mathrm{d}^{*}{ }_{\mathrm{Cr}}$ & 2.52 \\
$n_{\mathrm{O} 3} \rightarrow \mathrm{d}^{*}{ }_{\mathrm{Cr}}$ & 2.37 & $n_{\mathrm{O} 9} \rightarrow \mathrm{d}^{*}{ }_{\mathrm{Cr}}$ & 2.63 & $n_{\mathrm{O} 4} \rightarrow \mathrm{d}^{*}{ }_{\mathrm{Cr}}$ & 1.21 \\
\hline
\end{tabular}

calculations can be used to more deeply investigate the molecular basis for rationalizing the complexation reaction.

3.3. Natural Bond Orbitals Analysis (NBO). The NBO analysis provides information about the electronic structure of a complex. For example, the interaction between the occupied and vacant orbitals represents the deviation of the molecules from the Lewis structure, and the respective energies can be used as a measure of structure stability $[18,40]$. Table 4 shows the most energetic interactions involving the transfer of electrons between orbitals (donor $\rightarrow$ acceptor) and energies in the coordination sphere of the structures formed with $\mathrm{Cr}^{+6}$, through which it is possible to justify the difference in stability between the respective complexes. As can be seen, the interactions mentioned in relation to $\left[\mathrm{Cr}^{+6}\right.$ (EDTA)] complex are relatively much higher than the correspondents in the structures of the $\left[\mathrm{Cr}(\mathrm{NTA})\left(\mathrm{H}_{2} \mathrm{O}\right)_{2}\right]$ and [ $\mathrm{Cr}$ (collagen)] complexes. These results indicate a greater stability for the Cr-EDTA complex, being in accordance with the Gibbs free energy variation obtained from the thermodynamic cycle. In order to investigate the electronic and steric effects that modulate the complexation reaction with chromium ions, we have performed NBO and AIM calculations.

3.4. Quantum Theory of Atoms in Molecules (QTAIM). The topological analysis of the electron density can provide valuable information about the properties of the system under consideration. The properties of electron density measurements in the so-called Bond Critical Point (BCP), such as the 


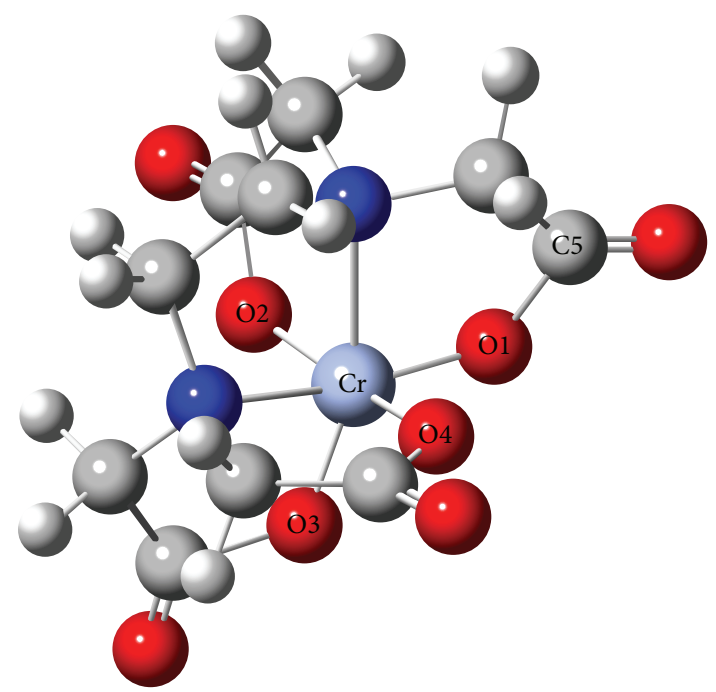

(a)

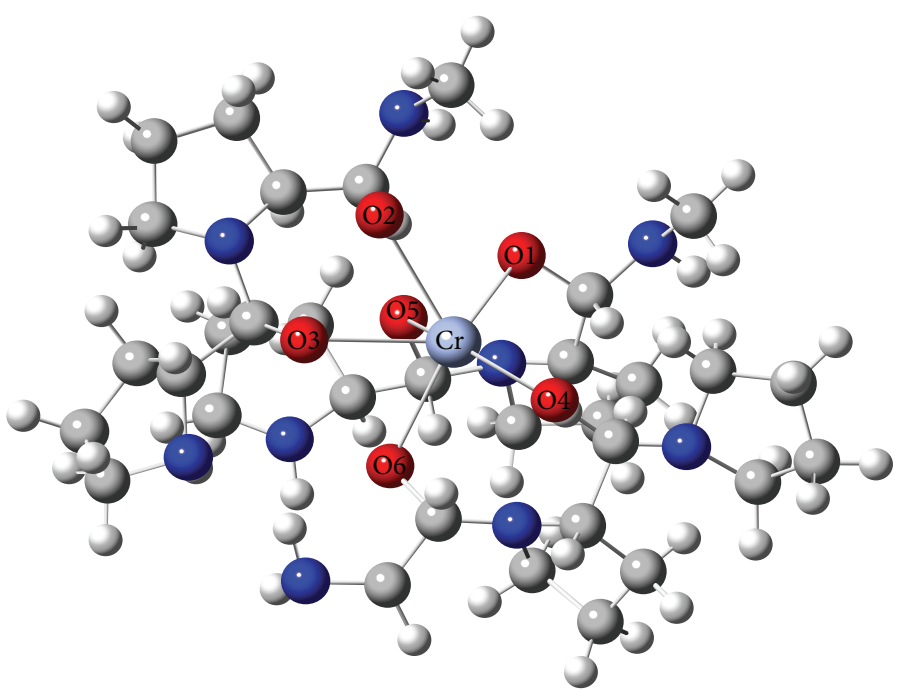

(b)

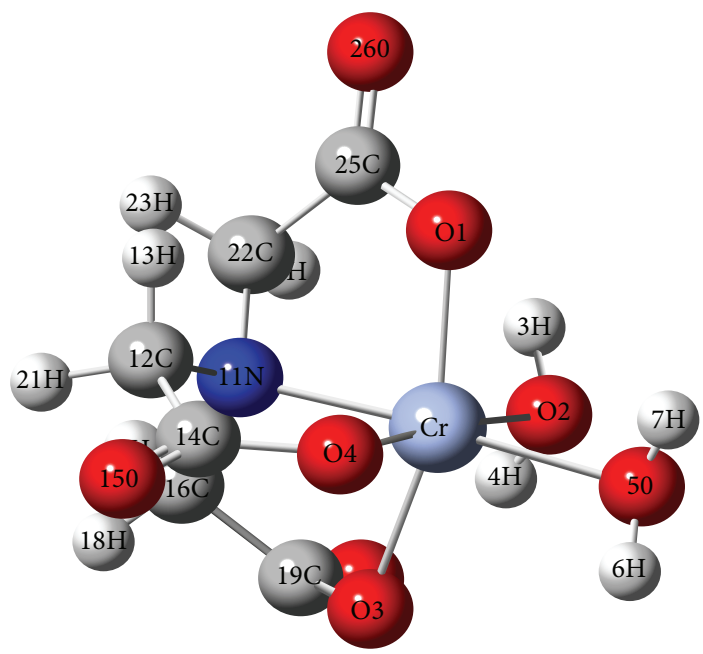

(c)

FIgURE 5: Structures of the isomer "B" of the Cr-EDTA complex (a), Cr-collagen complex (b), and Cr-NTA complex (c).

electronic density at BCP $(\rho)$, the Laplacian of the electron density $\left(\nabla^{2} \rho\right)$, the potential energy $(\mathrm{Vc})$, kinetic energy $(\mathrm{Gc})$, and the total electron energy $(\mathrm{Hc})$, are useful for detecting and characterizing the chemical bonds such as covalent bonds, metal-ligand interactions, hydrogen bonds, and other weak noncovalent intramolecular interactions [41]. For example, for bonds predominantly covalent, $\rho$ is generally $>0.20, \nabla^{2} \rho<0$, and $\mathrm{Hc}<0$, while for the bond of an electrostatic nature (ionic) $\rho$ is generally lower $\left(\sim 10^{-2}\right.$ for hydrogen bonding and $\sim 10^{-3}$ for Van der Waals interaction) with $\nabla^{2} \rho>0$ and Hc relatively higher [13, 42]. Table 3 shows the properties of BCPs for the most relevant interactions that occur among the atoms in the $\mathrm{Cr}^{+6}$ complexes shown in Figure 5. As with the data in Table 4, it can be seen that the interactions established between chromium and the oxygen atom are electrostatic in nature, with ionic bonding characteristics, wherein the core supports the entire load concentration $\left(\nabla^{2} \rho>0\right.$ and relatively high $\left.\mathrm{Hc}\right)$, in contrast, for example, with the values of the covalent bond O1-C5. The QTAIM analysis did not reveal relevant intramolecular interaction, such as hydrogen bonding, for example. However, the topological analysis revealed a greater electron density in the coordination sphere region for Cr-EDTA complex than with the complexes collagen-Cr and $\mathrm{Cr}-(\mathrm{NTA})\left(\mathrm{H}_{2} \mathrm{O}\right)_{2}$. Moreover, the electron density $(\rho)$ values in the coordination sphere of BCPs for these two complexes were much lower, indicating that electrostatic interactions are less.

\subsection{Formation Kinetics of Cr-EDTA Complex}

3.5.1. Experimental. Since our theoretical findings point out EDTA as the best ligand used for the complexation reaction with chromium at both oxidation states, $\mathrm{Cr}^{+3}$ and $\mathrm{Cr}^{+6}$, we have performed the experimental part focused on EDTA complex. The formation of the Cr-EDTA complex in relation to time can be evidenced by the gradual formation of its 


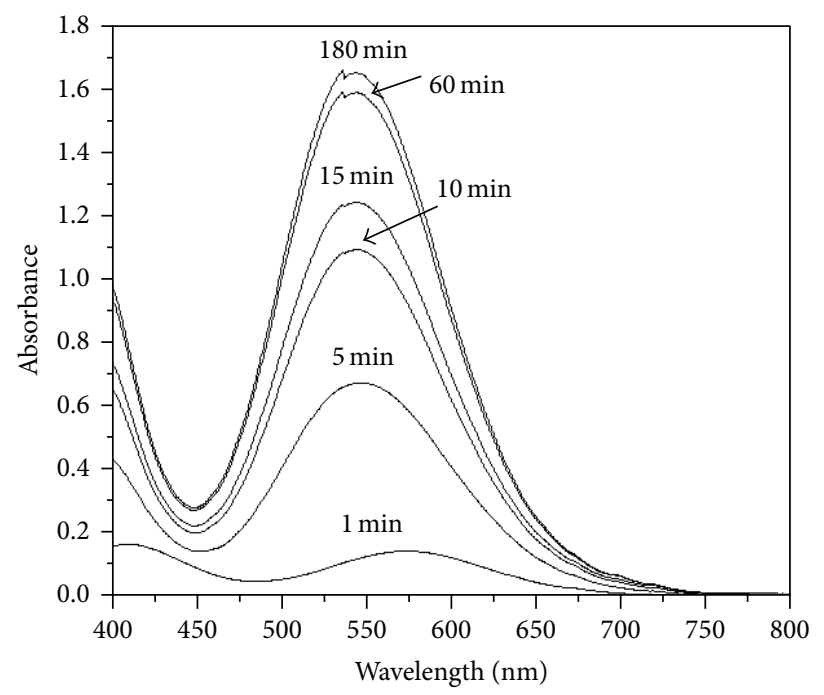

FIgUre 6: UV-Vis spectra of the Cr-EDTA complex at $70^{\circ} \mathrm{C}$.

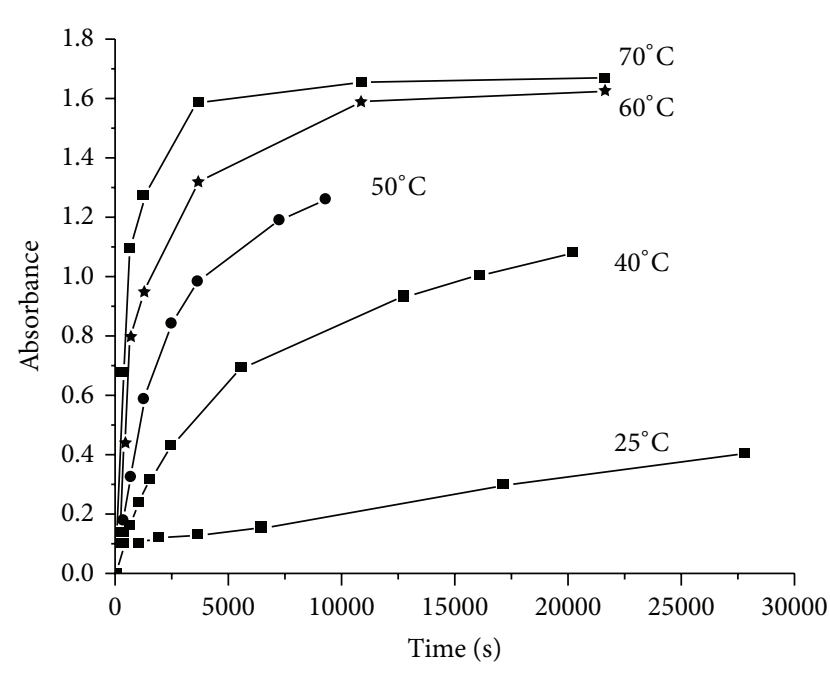

(a)

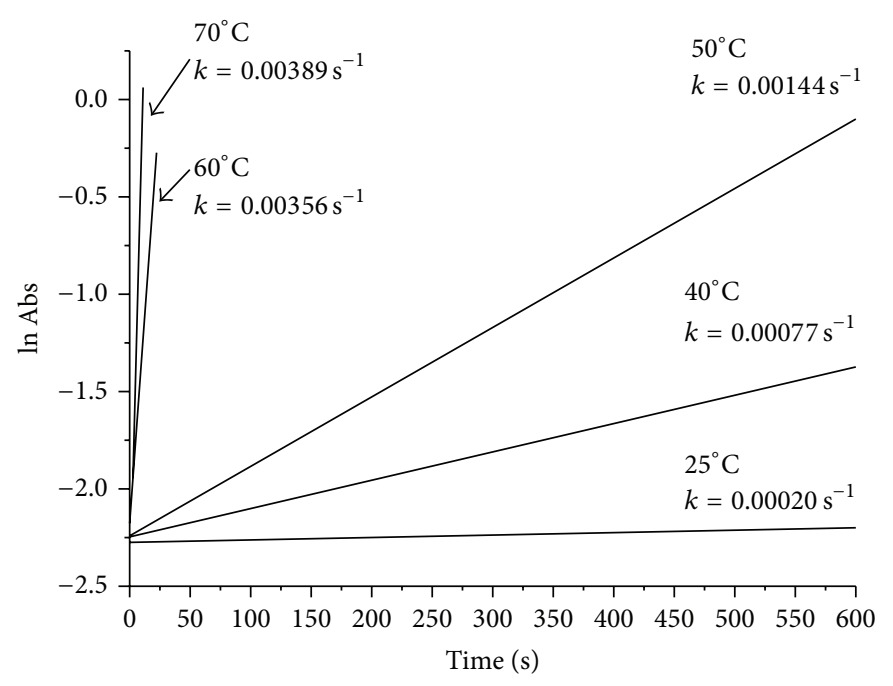

(b)

Figure 7: The formation kinetics of the Cr-EDTA complex at different temperatures (a) and the linearization of the equation speed (ln [Abs] $=k t$ ) with the respective constants (b).

absorption band in the visible region at $546 \mathrm{~nm}$ (Figure 6). The spectra show that at $70^{\circ} \mathrm{C}$ the formation of the complex can be studied with extreme speed; only $5 \mathrm{~min}$ of reaction is necessary. The formation kinetics of Cr-EDTA complex was studied at $546 \mathrm{~nm}$ at various temperatures, as shown in Figure 7(a). It can be observed that increasing the temperature increases the rate of complex formation, observing the increase in absorbance for the same time. In addition, considering an approximately linear curve in short times, one can determine the rate constants for complex formation, by linearizing the velocity equation $\ln [\mathrm{Abs}]=k t$, shown in Figure 7(b). Using the Arrhenius equation [43] (4) and with the data obtained in this experiment it was possible to determine the activation energy required for the formation of the complex $\left(E_{a}=59 \mathrm{~kJ} \cdot \mathrm{mol}^{-1}\right)$ :

$$
\ln K=\ln A-\frac{E_{\mathrm{at}} R}{T^{-1}} .
$$

3.6. Effect of $p H$. Complexation reactions involving metals by ligands of aminopolycarboxylic acids are very dependent on $\mathrm{pH}$, such that, according to the acidity of the reaction medium, there will be a greater or lesser prevalence of a species of ligand at equilibrium. At very low $\mathrm{pH}$ the nonionized species of the ligand predominates, so that, for the reaction to occur, the metal ions must be able to remove the ionizable hydrogens 
of the molecule. On the other hand, in strongly basic solutions, such hydrogens are removed by reaction with hydroxide ions. However, the ligand in its anionic form will "compete" with the hydroxyl in the complexation with the metal, and many metal ions tend to hydrolyze and precipitate as hydroxides [2]. The formation of $\left[\mathrm{Cr}^{+3}\right.$ (EDTA)] complex shows to be favored between $\mathrm{pH} 4.5$ and 7, and according to the basicity increase, the species is gradually replaced by $\left[\mathrm{Cr}^{+3}(\mathrm{EDTA})(\mathrm{OH})\right]$, tending to form the hydroxide $\mathrm{Cr}^{+3}$ [44].

\section{Conclusion}

In this work the stability of complexation of chromium (trivalent and hexavalent) with the structures of the polydentate ligands EDTA and NTA and collagen was studied. According to our results we observe that the formation of the Cr-EDTA complex from the $\mathrm{Cr}^{+6}$ is energetically more favorable; that is, the complex is more stable. The fact that the $\mathrm{Cr}^{+6}$ has a similar electronic configuration to a representative element and a smaller ionic radius compared to $\mathrm{Cr}^{+3}$ can justify this greater stability. The kinetics of formation of complex with $\mathrm{Cr}^{+3}$ was also investigated. The results showed that increasing the temperature increases the rate of formation of the complex and at $70^{\circ} \mathrm{C}$ only $5 \mathrm{~min}$ of reaction is required with a rate constant equal to $k=0.00389 \mathrm{~s}^{-1}$.

By comparing the Gibbs free energy of Cr-EDTA, $\left[\mathrm{Cr}(\mathrm{NTA})\left(\mathrm{H}_{2} \mathrm{O}\right)_{2}\right]$ and $\mathrm{Cr}$-collagen structures complexation, the following order of stability was found: $\left[\mathrm{Cr}^{+6}(\mathrm{EDTA})\right]>$ $\left[\mathrm{Cr}^{+3}(\mathrm{EDTA})\right]>\left[\mathrm{Cr}^{+6}(\mathrm{NTA})\left(\mathrm{H}_{2} \mathrm{O}\right)_{2}\right]>\left[\mathrm{Cr}^{+3}(\mathrm{NTA})\left(\mathrm{H}_{2} \mathrm{O}\right)_{2}\right]$ $>\left[\mathrm{Cr}^{+6}(\right.$ collagen $\left.)\right]>\left[\mathrm{Cr}^{+3}(\right.$ collagen $\left.)\right]$. Thus, in this work it was noticed that although the EDTA and NTA ligands can be used in the process, the formation of the Cr-EDTA complex is energetically more favorable; therefore, EDTA has greater ability to "sequester" $\mathrm{Cr}^{3+}$ as well as $\mathrm{Cr}^{6+}$, which are connected to the waste from the leather industry (chips, shavings, and dust from sanding) before they are discarded or reused for other purposes. Thus, from a thermodynamics, as well as kinetics point of view, our theoretical and experimental findings point out EDTA as a promising scavenger for chromium, forming a more stable metallic complex with chromium with a lower activation energy, from "wet blue" leather waste.

\section{Conflict of Interests}

The authors declare that there is no conflict of interest regarding the publication of this paper.

\section{Acknowledgments}

The authors thank the Brazilian agencies FAPEMIG, CAPES, and $\mathrm{CNPq}$ for funding part of this work.

\section{References}

[1] C. Durante, M. Cuscov, A. A. Isse, G. Sandonà, and A. Gennaro, "Advanced oxidation processes coupled with electrocoagulation for the exhaustive abatement of Cr-EDTA," Water Research, vol. 45, no. 5, pp. 2122-2130, 2011.

[2] R. Dai, J. Liu, C. Yu, R. Sun, Y. Lan, and J.-D. Mao, "A comparative study of oxidation of $\mathrm{Cr}$ (III) in aqueous ions, complex ions and insoluble compounds by manganese-bearing mineral (birnessite)," Chemosphere, vol. 76, no. 4, pp. 536-541, 2009.

[3] J. P. Thyssen, M. Strandesen, P. B. Poulsen, T. Menné, and J. D. Johansen, "Chromium in leather footwear-risk assessment of chromium allergy and dermatitis," Contact Dermatitis, vol. 66, no. 5, pp. 279-285, 2012.

[4] K. Kolomaznik, M. Adamek, I. Andel, and M. Uhlirova, "Leather waste-Potential threat to human health, and a new technology of its treatment," Journal of Hazardous Materials, vol. 160, no. 2-3, pp. 514-520, 2008.

[5] R. M. Dallago, A. Smaniotto, and L. C. A. de Oliveira, "Resíduos sólidos de curtumes como adsorventes para a remoção de corantes em meio aquoso," Química Nova, vol. 28, no. 3, pp. 433437, 2005.

[6] M. Erdem and A. Özverdi, "Leaching behavior of chromium in chrome shaving generated in tanning process and its stabilization," Journal of Hazardous Materials, vol. 156, no. 1-3, pp. 51-55, 2008.

[7] L. F. Cabeza, M. M. Taylor, G. L. Dimaio et al., "Processing of leather waste: pilot scale studies on chrome shavings. Isolation of potentially valuable protein products and chromium," Waste Management, vol. 18, no. 3, pp. 211-218, 1998.

[8] D. Q. L. de Oliveira, K. T. G. Carvalho, A. R. R. Bastos, L. C. A. de Oliveira, J. J. G. de Sá e Melo Marques, and R. S. de Melo Pereira do Nascimento, "Use of leather industry residues as nitrogen sources for elephantgrass," Revista Brasileira de Ciencia do Solo, vol. 32, no. 1, pp. 417-424, 2008.

[9] A. Kovács, D. S. Nemcsok, and T. Kocsis, "Bonding interactions in EDTA complexes," Journal of Molecular Structure: THEOCHEM, vol. 950, no. 1-3, pp. 93-97, 2010.

[10] M. Korolczuk and M. Grabarczyk, "Evaluation of ammonia buffer containing EDTA as an extractant for $\mathrm{Cr}(\mathrm{VI})$ from solid samples," Talanta, vol. 66, no. 5, pp. 1320-1325, 2005.

[11] C.-C. Liu and Y.-C. Lin, "Reclamation of copper-contaminated soil using EDTA or citric acid coupled with dissolved organic matter solution extracted from distillery sludge," Environmental Pollution, vol. 178, pp. 97-101, 2013.

[12] L. Chen, T. Liu, and C. Ma, "Metal complexation and biodegradation of EDTA and S,S-EDDS: a density functional theory study," The Journal of Physical Chemistry A, vol. 114, no. 1, pp. 443-454, 2010.

[13] I. Cukrowski and K. K. Govender, "A density functional theoryand atoms in molecules-based study of NiNTA and NiNTPA complexes toward physical properties controlling their stability. A new method of computing a formation constant," Inorganic Chemistry, vol. 49, no. 15, pp. 6931-6941, 2010.

[14] S. Cataldo, C. de Stefano, A. Gianguzza, and A. Pettignano, "Sequestration of $\left(\mathrm{CH}_{3}\right) \mathrm{Hg}^{+}$by amino-polycarboxylic chelating agents," Journal of Molecular Liquids, vol. 172, pp. 46-52, 2012.

[15] Z.-G. Shen, X.-D. Li, C.-C. Wang, H.-M. Chen, and H. Chua, "Lead phytoextraction from contaminated soil with highbiomass plant species," Journal of Environmental Quality, vol. 31, no. 6, pp. 1893-1900, 2002.

[16] S. C. Hoops, K. W. Anderson, and K. M. Merz Jr., "Force Field Design for Metalloproteins," Journal of the American Chemical Society, vol. 113, no. 22, pp. 8262-8270, 1991. 
[17] J. Šponer and P. Hobza, "MP2 and CCSD(T) study on hydrogen bonding, aromatic stacking and nonaromatic stacking," Chemical Physics Letters, vol. 267, no. 3-4, pp. 263-270, 1997.

[18] T. C. Ramalho, E. F. F. da Cunha, and R. B. de Alencastro, "A density functional study on the complexation of ethambutol with divalent cations," Journal of Molecular Structure: THEOCHEM, vol. 676, no. 1-3, pp. 149-153, 2004.

[19] P. Comba and R. Remenyi, "Inorganic and bioinorganic molecular mechanics modeling-the problem of the force field parameterization," Coordination Chemistry Reviews, vol. 9, pp. 238-239, 2003.

[20] P. Carloni and W. Andreoni, "Platinum-modified nucleobase pairs in the solid state: a theoretical study," Journal of Physical Chemistry, vol. 100, no. 45, pp. 17797-17800, 1996.

[21] M. S. Caetano, T. C. Ramalho, D. F. Botrel, E. F. F. da Cunha, and W. C. de Mello, "Understanding the inactivation process of organophosphorus herbicides: a DFT study of glyphosate metallic complexes with $\mathrm{Zn}^{2+}, \mathrm{Ca}^{2+}, \mathrm{Mg}^{2+}, \mathrm{Cu}^{2+}, \mathrm{Co}^{3+}, \mathrm{Fe}^{3+}$, $\mathrm{Cr}^{3+}$, and $\mathrm{Al}^{3+}$, International Journal of Quantum Chemistry, vol. 112, no. 15, pp. 2752-2762, 2012.

[22] W. S. Ohlinger, P. E. Klunzinger, B. J. Deppmeier, and W. J. Hehre, "Efficient calculation of heats of formation," The Journal of Physical Chemistry A, vol. 113, no. 10, pp. 2165-2175, 2009.

[23] T. A. Yousef, G. M. Abu El-Reash, and R. M. El Morshedy, "Structural, spectral analysis and DNA studies of heterocyclic thiosemicarbazone ligand and its $\mathrm{Cr}$ (III), $\mathrm{Fe}$ (III), $\mathrm{Co}$ (II) $\mathrm{Hg}$ (II), and U(VI) complexes," Journal of Molecular Structure, vol. 1045, pp. 145-159, 2013.

[24] F. Fontaine-Vive, F. Merzel, M. R. Johnson, and G. J. Kearley, "Collagen and component polypeptides: low frequency and amide vibrations," Chemical Physics, vol. 355, no. 2-3, pp. 141148, 2009.

[25] L. C. A. Oliveira, M. C. Guerreiro, M. Gonçalves, D. Q. L. Oliveira, and L. C. M. Costa, "Preparation of activated carbon from leather waste: a new material containing small particle of chromium oxide," Materials Letters, vol. 62, no. 21-22, pp. 37103712, 2008.

[26] M. J. Frisch, G. W. Trucks, H. B. Schlegel et al., Gaussian, Wallingford, Conn, USA, 2009.

[27] T. C. Ramalho, E. F. F. da Cunha, R. B. de Alencastro, and A. Espínola, "Differential complexation between $\mathrm{Zn}^{2+}$ and $\mathrm{Cd}^{2+}$ with fulvic acid: a computational chemistry study," Water, Air, and Soil Pollution, vol. 183, no. 1-4, pp. 467-472, 2007.

[28] M. Ghosh, S. Sproules, T. Weyhermüller, and K. Wieghardt, " $(\alpha$-diimine $)$ chromium complexes: molecular and electronic structures; a combined experimental and density functional theoretical study," Inorganic Chemistry, vol. 47, no. 13, pp. 59635970, 2008.

[29] R. Ditchfie, W. J. Hehre, and J. A. Pople, "Self-consistent molecular-orbital methods. IX. An extended Gaussian-type basis for molecular-orbital studies of organic molecules," Journal of Chemical Physics, vol. 54, p. 724, 1971.

[30] Y. I. Ishikawa and K. Kawakami, "Structure and infrared spectroscopy of group 6 transition-metal carbonyls in the gas phase: DFT studies on $\mathrm{M}(\mathrm{CO})_{n}(\mathrm{M}=\mathrm{Cr}, \mathrm{Mo}$, and $\mathrm{W} ; \mathrm{n}=6,5$, 4, and 3)," Journal of Physical Chemistry A, vol. 111, no. 39, pp. 9940-9944, 2007.

[31] H. Sun, X. Tian, J. Wang, J. Zhang, Y. Yuan, and Z.-R. Sun, "Theoretical studies on molecular and structures of mono- and binuclear chromium carbazole derivatives for optoelectronics," The Journal of Physical Chemistry A, vol. 115, no. 50, pp. 1449514501, 2011.
[32] K. Shimizu, A. A. Freitas, J. P. S. Farah, and L. G. Dias, "Predicting hydration free energies of neutral compounds by a parametrization of the polarizable continuum model," The Journal of Physical Chemistry A, vol. 109, no. 49, pp. 11322-11327, 2005.

[33] NBO, Version 5.0, Included in the Gaussian09 Package of Programs, Gaussian, Wallingford, Conn, USA, 2009.

[34] T. H. Dunning and P. J. Hay, "Gaussian basis sets for molecular calculations," in Modern Theoretical Chemistry, vol. 3, pp. 1-28, Plenum, New York, NY, USA, 1976.

[35] T. A. Keith, AIMAll (Version 11.10.16), TK Gristmill Software, Overland Park, Kan, USA, 2011, http://aim.tkgristmill.com/.

[36] R. E. Hamm, "Complex ions of chromium. IV. The ethylenediaminetetraacetic acid complex with chromium (III)," Journal of the American Chemical Society, vol. 75, no. 22, pp. 5670-5672, 1953.

[37] H. Irving and R. J. P. Williams, "The stability of transition-metal complexes," Journal of the Chemical Society, pp. 3192-3210, 1953.

[38] C. Quintelas, Z. Rocha, B. Silva, B. Fonseca, H. Figueiredo, and T. Tavares, "Removal of Cd(II), Cr(VI), Fe(III) and Ni(II) from aqueous solutions by an E. coli biofilm supported on kaolin," Chemical Engineering Journal, vol. 149, no. 1-3, pp. 319-324, 2009.

[39] M. S. Aksoy and U. Özer, "Potentiometric and spectroscopic studies with chromium(iii) complexes of hydroxysalicylic acid derivatives in aqueous solution," Turkish Journal of Chemistry, vol. 27, no. 6, pp. 667-673, 2003.

[40] T. C. Ramalho, T. L. C. Martins, L. E. Pizarro Borges, and J. D. Figueroa-Villar, "Influence of nonbonded interactions in the kinetics of formation of chalcogenol esters from chalcogenoacetylenes," International Journal of Quantum Chemistry, vol. 95, no. 3, pp. 267-273, 2003.

[41] B. Bankiewicz, P. Matczak, and M. Palusiak, "Electron density characteristics in bond critical point (QTAIM) versus interaction energy components (SAPT) - the case of charge-assisted hydrogen bonding," Journal of Physical Chemistry A, vol. 116, no. 1, pp. 452-459, 2012.

[42] P. R. Varadwaj and H. M. Marques, "The physical chemistry of $\left[\mathrm{M}\left(\mathrm{H}_{2} \mathrm{O}\right)_{4}\left(\mathrm{NO}_{3}\right)_{2}\right]\left(\mathrm{M}=\mathrm{Mn}^{2+}, \mathrm{Co}^{2+}, \mathrm{Ni}^{2+}, \mathrm{Cu}^{2+}, \mathrm{Zn}^{2+}\right)$ complexes: computational studies of their structure, energetics and the topological properties of the electron density," Theoretical Chemistry Accounts, vol. 127, no. 5-6, pp. 711-725, 2010.

[43] P. Atkins, Físico-Química, vol. 3 of H. Macedo, ed, chapter 2, LTC, Rio de Janeiro, Brazil, 1999.

[44] R. F. Carbonaro, B. N. Gray, C. F. Whitehead, and A. T. Stone, "Carboxylate-containing chelating agent interactions with amorphous chromium hydroxide: adsorption and dissolution," Geochimica et Cosmochimica Acta, vol. 72, no. 13, pp. 3241-3257, 2008. 

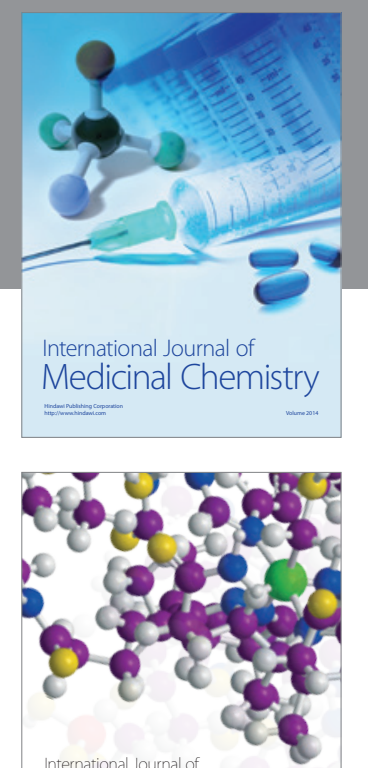

\section{Carbohydrate} Chemistry

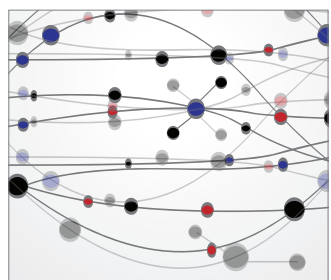

The Scientific World Journal
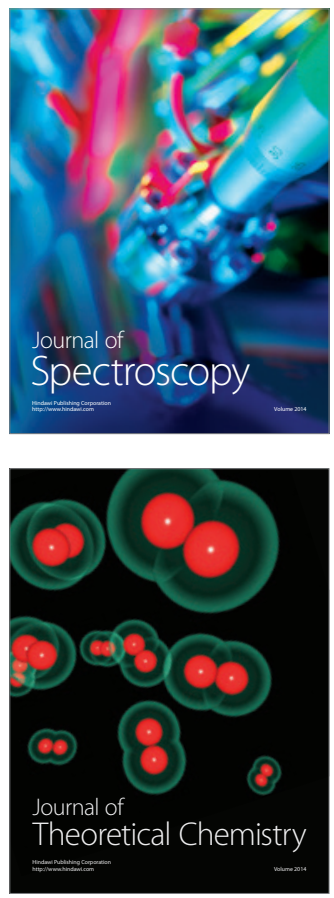
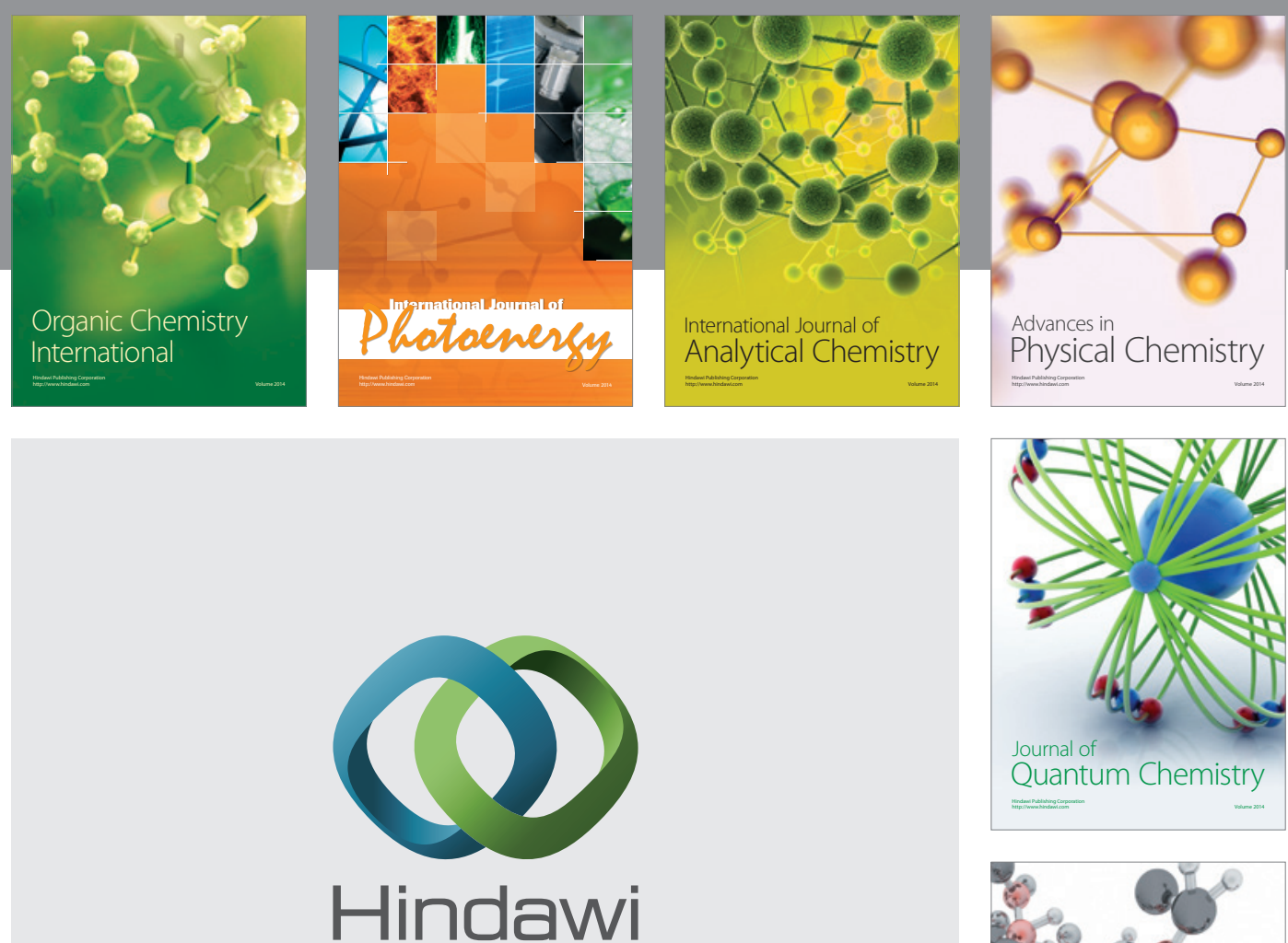

Submit your manuscripts at

http://www.hindawi.com

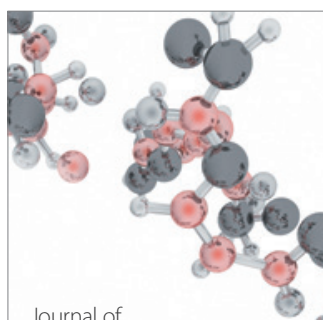

Analytical Methods

in Chemistry

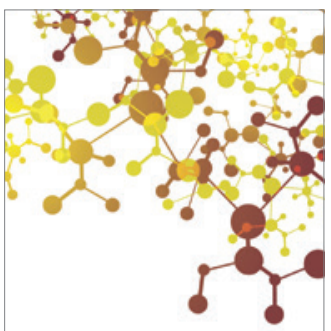

Journal of

Applied Chemistry

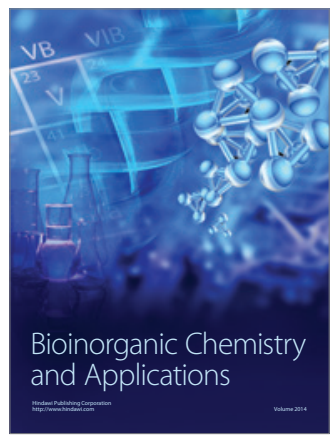

Inorganic Chemistry
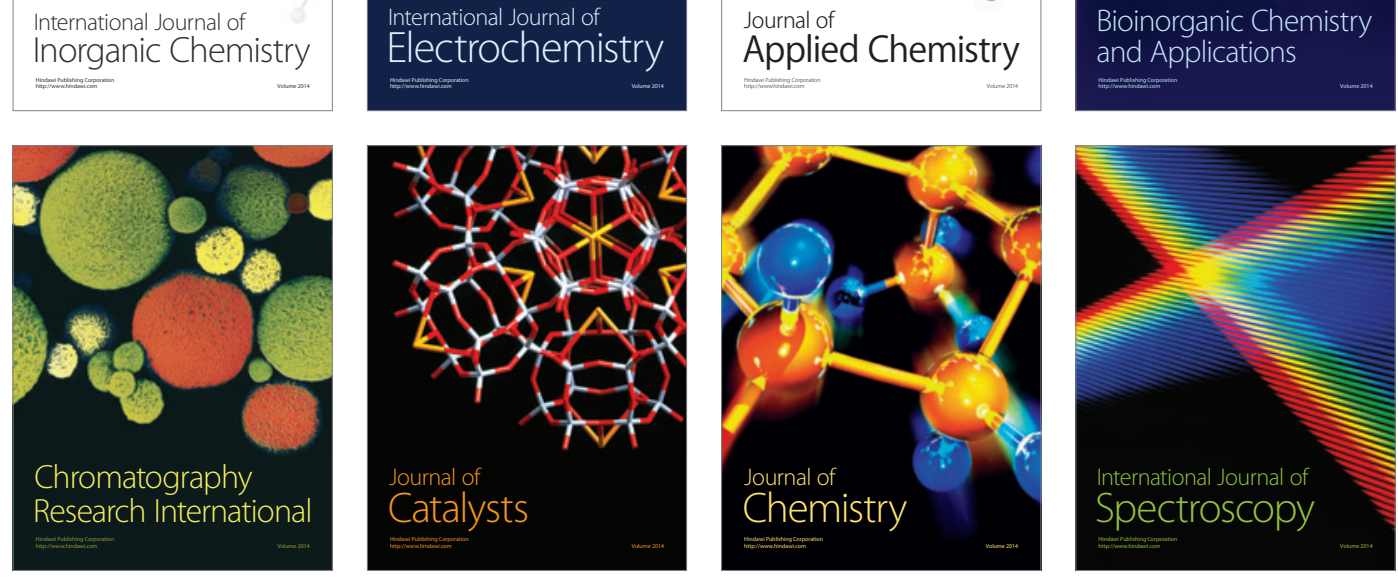